\title{
EL GUARDIÁN EN LA RESPONSABILIDAD POR RIESGO O VICIO DE LAS COSAS
}

\section{THE GUARDIAN IN THE RESPONSIBILITY FOR RISK OR VICE OF THE THINGS}

MARCELO J. LÓPEZ MESA

Universidad de Belgrano - Universidad Maimónides ARGENTINA 


\section{I) INTROITO}

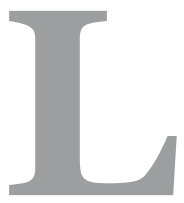

a responsabilidad por el hecho de las cosas es el arquetipo de la responsabilidad objetiva.

El Código Civil y Comercial dejó de lado en esta materia el esquema velezano, eliminando el concepto de daños causados por el hombre con la cosa y estableciendo un sistema objetivo, ultraobjetivo, cuyo eje es el art. 1757 CCC, en el que todo es riesgo creado o vicio de la cosa -más lo primero que lo último- y al que remiten diversas normas, como los arts. 1243 (responsabilidad del tomador o guardián de las cosas dadas en leasing), 1286 (responsabilidad del transportista de personas), 1685 in fine (responsabilidad del fiduciario), 1759 (daños causados por animales), 1769 (accidentes de tránsito). ${ }^{1}$

La noción de cosa es el eje sobre el que gira la responsabilidad del guardián, en el sistema del art. 1757 CCC; también es fundamental, en ese esquema, que la cosa haya jugado un papel activo en el origen del daño, pues si ella ha sido un instrumento utilizado por un hombre a designio para dañar, ya no estamos en el régimen de esa norma, sino en otros planos del derecho y en otros sistemas de responsabilidad. ${ }^{2}$

El concepto de riesgo que utiliza el art. 1757 CCC implica la operatividad probable de un objeto como vector generador de daños; pese a que pareciera difícil pensar en un objeto peligroso con abstracción de sus circunstancias de empleo, existen determinadas cosas que si bien no son riesgosas en su esencia, o por estar mal ubicadas o ser impulsadas por una fuerza motriz, generan peligrosidad capaz de provocar daños de tal entidad que su control resulta de muy difícil realización.

Las cosas pueden ser riesgosas por su propia naturaleza o por las circunstancias de su empleo, o por su ubicación. En este caso, una cosa en sí misma no riesgosa, ubicada peligrosamente, por ejemplo un automotor u obstáculo colocado sobre la ruta de noche o en otra ubicación peligrosa, puede convertirse en una seria fuente de daños. ${ }^{3}$

En cambio, el concepto de "vicio de la cosa" presupone un defecto de fabricación o funcionamiento que la hace impropia para su destino normal.

La responsabilidad fundada en el vicio de la cosa exige que un defecto de ésta, aparente u oculto, sea el factor determinante del daño, porque sólo así puede comprometer a quien ha mantenido la cosa en ese modo de ser vicioso y, por ende, potencialmente dañoso. ${ }^{4}$

\footnotetext{
${ }^{1}$ LÓPEZ MESA, Marcelo, “Curso de Derecho de Obligaciones”, Edit. Hammurabi, Buenos Aires, 2018, T. II, capítulo 24.

2 En un caso tal se dijo que el titular del automotor que fue utilizado por su conductor para lesionar intencionalmente al actor debe ser eximido de responder por las consecuencias dañosas de tal accionar, pues la causa del daño no fue el riesgo o vicio del rodado sino que fue su conductor quien lo utilizó diestramente para causar daño y contra la voluntad del titular dominial, cuyo permiso o tolerancia no pueden suponerse ni presumirse en las circunstancias en que se llevaron a cabo los hechos (Cám. 2a Civ. Com. La Plata, sala I, 29/03/2016, “B. D., F. L. C. C., S. E. y otros”, RCyS 2016-X, 145).

${ }^{3}$ En un caso tal se aseveró que acreditada la presencia de maderas sin medidas de seguridad colocadas unas encima de otras, en medio de un fuerte viento, para eximirse de responsabilidad el dueño o guardián de la cosa debe demostrar el hecho de la víctima o de otra persona por la que no debe responder o el caso fortuito ajeno a la cosa que fracture la relación causal (Cám. Civ. Com. Fa, y Contadm. Villa María, 20/04/2017, “Gue, Solange Rocio c. New Truck S.A. s/ ordinario”, LLO AR/JUR/14826/2017). ${ }^{4}$ CNCiv., Sala A, 2/3/94, “Consorcio Pueyrredón 1751/53/55 y otros c/ Consorcio Pueyrredón 1741/43/45 y otros", JA 1994-IV-590.
} 
El art. 1758 CCC, complementando al artículo anterior verdadero eje del sistema de responsabilidad civil del nuevo ordenamiento, legitima pasivamente en forma concurrente al dueño y al guardián de una cosa riesgosa o viciosa.

El concepto de dueño no genera mayor inconveniente, salvo en lo que toca a automotores, pues existe alguna jurisprudencia que denomina dueño a quien solo es poseedor, al no haber transferido registralmente el dominio del vehículo a su nombre. Tratándose de cosas registrables, el dueño es quien tiene el bien inscripto a su nombre en el registro respectivo. Por ende, seguidamente nos enfocaremos en la figura del guardián.

\section{II) EL GUARDIÁN}

La responsabilidad del guardián de una cosa no es un concepto nuevo en el derecho, sino que presenta antecedentes antiquísimos, incluso anteriores a la propia Roma, aunque más relevantes todavía en el derecho de ésta.

Más cercano en el tiempo, el maestro DOMAT enseñaba que "El orden que liga a los hombres en sociedad obliga... a cada uno a tener todo lo que posee en un estado tal de que nadie reciba ni mal ni daño". ${ }^{5}$

El incumplir este deber preventivo que pesaba sobre el guardián sobre sus cosas, si sobrevenía un daño antijurídico a otros, lo tornaba responsable del menoscabo.

El concepto de guardián es esencial para la puesta en juego del dispositivo del art. 1757 CCC, cuando el dueño no es el legitimado pasivo o no es el único legitimado pasivo a quien le es imputable la causación del daño. ${ }^{6}$

Pero, de antemano, debe puntualizarse que el segundo de los legitimados pasivos del art. 1757 CCC presenta un carácter borroso, apareciendo como una noción huidiza o inasible, cuando no como la imagen de un caleidoscopio, que muta absolutamente al menor movimiento. Tan importante figura jurídica no ha sido objeto de una definición precisa (ni por el art. 1113 del Código de Vélez, ni por el art. 1757 CCC).

La esencia y envergadura de la figura del guardián, al no estar expresamente definido legalmente el punto, es determinada por la magistratura por contraposición, debiendo recurrirse para ello a dos arbotantes o bases suplementarias, cuyo apoyo está, una en el régimen de los derechos reales y otra en el de los contratos.

El concepto se define, en primer lugar, por la negativa: al guardián a que se refiere el art. 1757 CCC no es aquél que tiene un derecho real sobre la cosa. Ese es guardián en tanto dueño, pero dada la doble condición y el carácter no acumulable de ambas legitimaciones, la de guar-

${ }_{5}^{5}$ DOMAT, Jean, "Les loix civiles dans leur ordre naturel; le droit public et Legum delectus [...]. Nouvelle édition, revue, corrigée et augmentée", París, Edit. Despilly, 1767, Partie I, Livre 2, Titre 8, Section 2.

${ }^{6}$ PORCHY-SIMON, Stéphanie, «Droit civil. Les obligations», Edit. Dalloz, 5a edic., París, 2008, p. 328, Nro. 685. 
dián se torna accesoria, prescindible y superficial, por ende, irrelevante a los efectos de esta norma, al ser absorbida por la legitimación principal.

Es que como se trata de legitimaciones excluyentes -cuando se dan en una misma perso$n a$ - la condición de dueño torna irrelevante la de guardián, porque jurídicamente todo dueño es guardián de la cosa de su propiedad, salvo que se haya producido una transferencia de la cosa, tema que dará lugar a un estudio posterior, por aparte del presente.

Existe incluso una presunción de que todo dueño o propietario de una cosa es guardián de ésta, en tanto garante de su inocuidad 7 ; pero responderá como dueño, en tanto no demuestre que ha transferido la propiedad o la guarda debidamente o que la cosa le ha sido arrebatada contra su voluntad, sin culpa de su parte.

En segundo lugar, el apoyo más firme para esta precisión liminar, se encuentra en el derecho de los contratos: guardián es normalmente todo aquél que por una cláusula contractual o una situación de hecho equiparable, tiene una cosa en nombre de otro; guardián es todo tenedor.

Es muy dudoso, en cambio, si el detentador, es decir quien ocupa la cosa o está autorizado a emplearla por razones de hospitalidad es guardián de ella. ${ }^{8}$

Si bien tiene un importante componente jurídico, el concepto de guardián, en ocasiones, posee en gran medida un componente de carácter fáctico. Es una facticidad revestida de algunos contenidos jurídicos, en suma. La pura facticidad es, de ordinario, insuficiente para configurar una guarda, pero también es inviable una guarda puramente jurídica, despojada de la materialidad de la posibilidad efectiva del control y dirección de la cosa.

Desde el arrêt Franck dictado por la Corte de Casación francesa el 2 de Diciembre de 1941, la jurisprudencia ha receptado en principio un diseño material de la guardia, criterio que no ha cambiado desde entonces. ${ }^{9}$

La determinación del carácter de guardián es, así, más una cuestión fáctica que jurídica, pues el hecho de una cosa incluso robada puede comprometer la responsabilidad de su guardián irregular, quien la robó o apropió indebidamente.

La guarda ha sido definida magistralmente por LE TOURNEAU en un párrafo que merece transcribirse: "La guarda se caracteriza por el poder de uso, de control y de dirección... Las tres expresiones son más o menos sinónimas, y la jurisprudencia no busca aplicarlas distintamente. Más globalmente, la guarda implica la dominación o señorío sobre la cosa. El uso, es el hecho de servirse de la cosa, en su interés, en ocasión de su actividad, cualquiera que sea, incluida la

\footnotetext{
${ }^{7}$ LE TOURNEAU, Philippe, "Droit de la responsabilité et des contrats ", 8a edic. Dalloz, París, 2010, p. 1695, Nro. 7837; BRUN, Philippe, "Responsabilité civile extracontractuelle”, 3a edic. Edit. Litec - Lexis Nexis, París, 2014, p. 246, Nro. 374.

${ }^{8}$ El detentador es una especie de tenedor precario, que representa la posesión de otro, sin derecho alguno más que la ocupación, por razones de hospitalidad. Bien se ha dicho que el concepto de precario comprende tanto el supuesto clásico de posesión obtenida por pura concesión a ruegos del detentador, como las cosas de posesión meramente de la pura condescendencia del dueño, como finalmente, los supuestos de posesión sin título o con título ineficaz para enervar el ius posidendi del demandante (cfr, fallo de la Audiencia Provincial de Gerona, 9 Oct. 1980, Ponente: Sr. Marañón) RJC, I-1981, 36 y mi voto, en sentencia de la Cám. Apels. Trelew, Sala A, 13/11/2012, "Transporte Ceferino S.R.L. c/ Construcciones Tierras Patagónicas S.R.L. s/ Desalojo", en https:// www.eldial.com/nuevo/index.asp

${ }^{9}$ Corte de Casación francesa, 2 a Sala Civil, 4/12/2008, № de pourvoi: 07-17622, en http://legifrance.gouv.fr/affichJuriJudi.do?oldA ction=rechJuriJudi\&idTexte=JURITEXT000019879437\&fastReqld=2123993698\&fastPos=1
} 
profesional. El control significa que el guardián puede vigilar la cosa, e inclusive, al menos si él es un profesional, que tiene la aptitud para impedir que ésta cause daños. Finalmente, la dirección manifiesta el poder efectivo del guardián sobre la cosa: él puede utilizarla a su gusto, hacerla desplazar hacia donde él lo desea, de manera independiente. La guarda implica pues la autonomía del guardián. Del arrêt Franck se deduce que la guarda no es jurídica sino material. Es un simple poder de hecho, apreciado concretamente en cada especie. Igualmente, su duración importa poco: basta que ese poder dure un instante de razón, suficiente para que el señorío o dominación sobre la cosa por parte del guardián haya podido realizarse (no es el caso de un alpinista que al

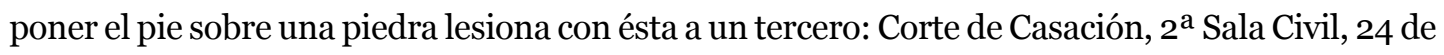
abril de 2003, Sabry, Bull. civ. II, $\mathrm{N}^{\circ}$ 116). Poder de hecho, la calidad de guardián puede incumbir tanto a una persona física como a una persona moral". ${ }^{10}$

Las cosas abandonadas o sin dueño no encuadran en el esquema del art. $1757 \mathrm{CCC}$, salvo cuando esas cosas hubieran sido dejadas en ubicaciones peligrosas sitas en lugares públicos, como una calle, ruta o camino, supuesto en que el guardián de la vía, pasa a ser el guardián de la cosa o, al menos, el encargado de velar por la inocuidad de la misma y por la pronta supresión de su ubicación peligrosa, siendo responsable en caso de no arbitrar los medios para evitar que ésta dañe a terceros.

El guardián de una cosa inanimada es, a una misma vez, guardián de diversos extremos de hecho:

a) guardián del riesgo y funcionamiento de la cosa;

b) guardián del vicio de construcción y del adecuado mantenimiento de la misma; y

c) en las cosas inertes, guardián del sitio de colocación de las mismas.

El guardián de una cosa viciosa, en primer lugar y arquetípicamente, es la persona que, de hecho, usa, emplea, disfruta o aprovecha y/o conserva y mantiene la cosa por su propia cuenta y que dispone sobre ella de un poder de vigilancia, de contralor y de dirección. ${ }^{11}$

Esta enumeración de poderes sobre la cosa es una indicación no taxativa de los más importantes de ellos y es, a la vez, una mención alternativa, esto es, no se requiere que se reúnan a una misma vez todas ellas, sino que para ser guardián basta con que se use la cosa, se la disfrute o aproveche, se la conserve o se tenga sobre ella un poder de vigilancia, de control o de dirección.

Claro que es indispensable que el guardián tenga, al momento del hecho dañoso, por sí o a través de empleados o subalternos, el control de la cosa que él utiliza, de la que saca provecho o le asegura su mantenimiento. Una guardia sin ese imprescindible y estrecho contacto o cercanía -material o intelectual- con la cosa es una ficción.

El juez apreciará en su sentencia si al momento del daño ese poder existía o no, rechazando la demanda en caso negativo ${ }^{12}$. La guarda no es una ficción, ni puede cobijarse bajo ese concepto cualquier artificio, irrealidad o desatino.

${ }^{10}$ LE TOURNEAU, Philippe, «La responsabilité civile», PUF, París, 2003, pp. 119/120.

${ }^{11}$ CORNELIS, L., “Principes du droit belge de la responsabilité extracontractuelle”, vol. I, “L' acte illicite”, Bruxelles, Bruylant et Ced. Samson, Antwerpen, Maklu, N²81, p.483.

12 LE TOURNEAU, Philippe, « Droit de la responsabilité et des contrats», cit, p. 1694, Nro. 7833. 
Claro que esta noción de control material sobre la cosa, que configura la primera de las formas de guarda - y la más corriente - debe analizarse evidentemente a la luz de las circunstancias concretas de cada caso, conservando los jueces un amplio poder de apreciación acerca de esta cuestión de hecho, a condición de que no violen la noción de guardián o construyan artificios conceptuales a partir de irrealidades evidentes, para extenderla hasta el infinito, jugando con las palabras.

Esta primera forma de guarda es, también, la primera que enuncia el art. $1758 \mathrm{CCC}$ in medio, que indica “...Se considera guardián a quien ejerce, por sí o por terceros, el uso, la dirección y el control de la cosa...”.

Obviamente, no basta para constituirse en guardián que la persona tuviera el control de la cosa; todavía hace falta, además, que ella disponga de un poder de vigilancia, de dirección y de control, con respecto a la cosa.

No necesariamente esas facultades directrices deben ser materiales; también hablamos de dirección intelectual de la cosa, la que permite controlar el uso y el empleo, por caso, a través de subalternos.

De tal modo, el guardián no debe necesariamente tener personalmente la custodia material de la cosa, aunque -de hecho- muchos guardianes suelen tenerla. Así, el consorcio de copropietarios, o una sociedad comercial o asociación civil es, a menudo, calificada por los jueces de guardiana de las partes comunes de un edificio, en el primer caso, o de las cosas de que se sirve para llevar adelante su actividad social, en los dos restantes. ${ }^{13}$

Tampoco es exigible que el guardián disponga de conocimientos técnicos especiales necesarios para remediar su vicio; tampoco se requiere el conocimiento de la existencia de un vicio de construcción o mantenimiento de la cosa para comprometer la responsabilidad del guardián; ello, pues la ignorancia del vicio no excluye la responsabilidad del guardián. Y, finalmente, el guardián puede tener sólo un control o dominio temporal de la cosa, bastando que lo haya tenido al momento del hecho dañoso. ${ }^{14}$

De tal suerte, debe ser considerado como guardián quien, al momento del hecho dañoso, disponía -por alguna razón de hecho o jurídica- del poder, la ocasión y la posibilidad, de tomar iniciativas con respecto a la cosa, de determinar su suerte o comportamiento, mantenerla, proveer a su reparación o a su sustitución y/o evitar que ella se pierda, se corrompa o dañe a otros.

La guarda es, entonces, una obligación impuesta a una persona, que tiene determinada relación con una cosa, la que consiste básicamente en vigilar esa cosa, para evitar que la misma sea sustraída, se deteriore o dañe a otros (vgr. el depositario tiene una obligación de guarda y también la tienen los otros tenedores de la cosa a nombre de otro, como el locatario, el usufructuario, etc).

\footnotetext{
${ }^{13}$ Así, se dijo en un fallo que el consorcio de propietarios demandado responde por los daños derivados de una explosión clandestina de gas realizada en el sótano del edificio - en ese caso, concurrentemente con el propietario y el gasista que hicieron la instalación-, pues, como guardián de las cosas comunes, no debió permitir el acceso de cualquier propietario a lugares de ingreso restringido, como lo es la sala de máquinas, por el eventual riesgo de manipulación de elementos peligrosos que pudieran hacerse (C. Nac. Civ., sala K, 13/10/2017, “O., D., G. c. P., C. A. s/ daños”, LLO, AR/JUR/79319/2017).

${ }^{14}$ Vgr. Corte de Casación francesa, 1a Sala Civil, 20/3/2003, en http://www.copropriete-ejuris.be/files/Copropriete-gardienchose-63.pdf
} 
La guarda consiste en un poder de control y dirección sobre una cosa que se utiliza o tiene bajo el cuidado, debiendo aclararse que dicho poder de control y dirección constituye una condición de existencia de la responsabilidad civil del guardián, si la cosa está en el origen del daño. ${ }^{15}$

Es que quien no tiene la cosa bajo su poder de control y dirección no puede ser efectivamente su guardián, con lo que atribuirle responsabilidad por guarda deficiente implica una vana sofistería, si no una cruel ironía.

Lo dicho hasta aquí no parece demasiado complejo. Aun así, cabe aclarar que no es tan difícil definir qué es la guarda, como determinar en ciertos casos concretos quién es allí el guardián y, por ende, uno de los legitimados pasivos del reclamo de daños.

El Código Civil y Comercial, lejos de haber zanjado la cuestión, la ha complicado, por un lado, al receptar como equivalentes a todas las formas de guarda: el uso, la dirección y el control de la cosa y el provecho que se obtiene de ella.

Pero, en segundo plano y más reflexivamente, el nuevo CCC ha simplificado la cuestión, pues basta con probar el uso de la cosa, para que se tenga al usuario como guardián.

Consideramos que, dada la forma en que la Comisión de reformas redactó el art. 1758 CCC, el primer supuesto, esto es, la guarda material en cabeza del principal, quien ejerce, por sí o por terceros, el uso de la cosa, habrá de tener necesaria preeminencia sobre los otros tipos de guarda, porque será mucho más fácil probar el uso de la cosa, que la dirección y control de ella o el provecho.

Basta que se pruebe el uso de la cosa, para que esa persona sea considerada guardián; y, si no lo es, por ejemplo, por ser empleado de otra persona, deberá alegar y probar ello al ser requerido como guardián, so pena de que tal título le quede en firme sobre él, con las consecuencias y responsabilidades inherentes.

Ergo, serán las circunstancias del caso, entonces, las que ameritarán cuál doctrina se aplica, lo que trae más problemas que soluciones, dada la indeterminación de un concepto central, axial en materia de responsabilidad por el hecho de las cosas, que se potencia ante la novedad de los textos y la carencia de pautas para interpretarlos, en los primeros años posteriores a su entrada en vigencia.

El CCC ha venido a sumar así la guarda material a la guarda-poder de mando y a la guarda-provecho, lo que significa una aligeración de los requisitos y complejidades para la determinación de la calidad de guardián.

Cabe acotar que, con el nuevo texto del art.1758 CCC, el discernimiento ya no es un requisito para la adquisición de la guarda, dado que el primer parámetro o tipo de guarda que recepta es la guarda material, que no requiere de discernimiento, ya que hasta una persona privada de razón o sin edad para comprender los alcances y efectos de sus actos puede usar una cosa.

El régimen vigente simplifica la determinación del guardián de la cosa; pero, dado el extremo esquematismo de la reforma en este aspecto, su sanción puede dar lugar a diversos

\footnotetext{
${ }^{15} \mathrm{Cfr}$. https://actu.dalloz-etudiant.fr/a-la-une/article/responsabilite-du-fait-des-choses-abandon-de-la-theorie-de-lacceptationdes-risques/h/4592f8dcc5b448ea06637e7890aad733.html
} 
interrogantes en esta materia, los que solamente la jurisprudencia posterior y detenidas reflexiones podrán -tal vez- evacuar.

La calidad de guardián de una cosa puede ser asignada a diversos títulos. El primer guardián de una cosa es su propietario o titular de derechos reales; paradójicamente éste no responde como guardián, sino como dueño o poseedor, ya que tal calidad desplaza a la guarda, al presuponerla o llevarla implícita.

Pero suele asumirse la calidad de guardián en virtud de obligaciones personales, de tipo obligacional. Así, el contrato de locación confiere en principio al locatario poderes que lo convierten en guardián de la cosa locada, que es objeto del contrato, en la medida de los poderes y facultades que el inquilino tiene sobre la cosa alquilada (cfr. art. 1206 y 1207 CCC).

En cuanto al resto, dado que el locatario no tiene plenitud de facultades sobre la cosa, los poderes que conserva el dueño de la cosa como locador, lo convierten a éste en guardián de la misma, al menos en cuanto a sus facultades conservadas toca (arts. 1201 y cctes. CCC). Cabría en estos supuestos aplicar, por caso, la doctrina de la guarda dividida.

La guardia dividida no puede ser una invención, una conjetura, pero cuando es el propio legislador el que divide las esferas de actuación legítima de diversos sujetos, cabe estar a su determinación de poderes, para fijar el alcance o extensión de la guarda y su eventual división.

Esta división no es un desatino en algunos segmentos del derecho argentino vigente, si se piensa que el propio Código es el que asigna determinadas facultades y obligaciones correlativas de custodia de la cosa locada al locatario, mientras mantiene otras en cabeza del locador, estableciendo un sistema de frenos y contrapesos de los poderes y facultades de éstos.

El criterio que permite determinar cuándo el locatario asume la guarda de la cosa alquilada debe buscarse en la extensión del poder de mando respecto a esa cosa alquilada, de acuerdo a sus características y a los términos del contrato respectivo o de la legislación supletoria aplicable, cuando este poder se ejercita sobre las cosas con respecto a las cuales una obligación de mantenimiento y vigilancia le es impuesta al inquilino.

Lo propio ocurre con usufructuarios, usuarios, comodatarios y quienes tienen derecho de habitación sobre la cosa, quienes son guardianes de ella, en la medida de los poderes y facultades que les confiere el ordenamiento civil, mientras que el propietario sigue siendo guardián, en lo concerniente a los suyos, aún cuando, en su caso, responderá como propietario y no como guardián.

Como sea, es innegable que el concepto de "guardián" de una cosa ha generado grandes debates y cuestionamientos. Pero, aun así, no es tan dificultoso comprender el alcance del concepto de guarda como establecer cuáles son las condiciones o requisitos necesarios para ser guardián de la cosa y, más aún, determinar puntualmente quién es el guardián de determinadas cosas. Ahí radica la auténtica complejidad del asunto.

Es que, "por principio, la calidad de guardián debe ser fijada en concreto y determinando quién ejerce los poderes de uso, de control y de dirección sobre la cosa, al momento del daño. La jurisprudencia presume siempre que el propietario es el guardián. Pero esta presunción 
simple es relativa y susceptible de prueba en contrario. La determinación del guardián suscita dificultades particulares en diversas hipótesis de importancia innegable". ${ }^{16}$

Una de las primeras complejidades finca en la dilucidación de si un empleado puede ser guardián de una cosa. Nos apresuramos a anticipar que la respuesta es negativa a nuestro juicio.

Bien se ha señalado con relación al derecho francés, pero con plena aplicabilidad al nuestro, que "la noción de guarda es una noción jurídica sin relación con el sentido de este término en la lengua corriente. Conviene prestar atención a esta dificultad de terminología. En la lengua corriente, un guardián es un empleado a quien se le ha confiado el cuidado de velar por una cosa. En derecho, un empleado no puede jamás ser guardián de una cosa de su patrón; este último es el que permanece como guardián mientras él conserve la autoridad". ${ }^{17}$

En la senda correcta y en agudísimos conceptos ha dicho el maestro LE TOURNEAU que "el empleado, de larga duración, en tanto está bajo la subordinación del comitente, no tiene el poder de control y de dirección de la cosa y, si bien, la usa, no lo hace en su interés directo. El guardián sigue siendo el principal, aún si el empleado goza de una gran autonomía. Las calidades de empleado y de guardián de una cosa del comitente son incompatibles". ${ }^{18}$

Incluso quienes no comparten el criterio reconocen que "la incompatibilidad entre las calidades de guardián y empleado aparece como una de las islas de estabilidad en nuestro derecho contemporáneo de la responsabilidad civil". ${ }^{19}$

Este principio invariable de la jurisprudencia francesa de que el empleado no puede ser guardián de una cosa de su principal fue sentado por primera vez el 27 de febrero de 1929, en que en un célebre arrêt se estableció la regla -desde entonces inamovible- de que en caso de daño causado por un empleado por medio de una cosa o un animal, solo el comitente puede ser declarado guardián y, a ese título, ver su responsabilidad comprometida sobre la base del art. 1384, primera parte 01385 del Código Napoleón. ${ }^{20}$

Desde entonces la incompatibilidad entre las calidades de guardián y de empleado ha sido neta y constantemente reafirmada, pudiéndose citar numerosos precedentes en el mismo sentido ${ }^{21}$ y prestigiosa doctrina en la misma senda ${ }^{22}$, tesitura que compartimos.

\footnotetext{
${ }^{16}$ PORCHY-SIMON, Stéphanie, «Droit civil. Les obligations», cit, p. 329, Nro. 690.

${ }^{17}$ MALINVAUD, Philippe, "Droit des obligations", cit, p. 449, Nro. 619.

${ }^{18}$ LE TOURNEAU, Philippe, "Droit de la responsabilité et des contrats», cit, p. 1696, Nro. 7838.

${ }_{19}$ PEANO, Marie-Annick, “L'incompatibilité entre les qualités de gardien et de préposé”, en Recueil Dalloz, 1991, sec. Chroniques, p. 51.

${ }^{20}$ Cfr. Corte de Casación francesa, sala Civ., 27/2/1929, en Dalloz Périod., t. 1929-.1, p. 129, con nota del maestro Ripert y en el Recueil Sirey, t. 1929-1.297, con nota de Hugueney.

${ }^{21}$ Por solo citar algunos precedentes, vid. Corte de Casación francesa, sala Civ., 29/12/1947, en Dalloz, t. 1948. p. 127; idem, 2a sala Civil, 11/5/1956, Dalloz 1957, p. 121, con nota de Rodière; ídem, 16 y 17/3/1960, en Gazzette du Palais, t. 1960-2, p. 57; ídem, 4/11/1965, Dalloz, t. 1966, p. 394, con nota de Plancqueel; ídem, 19/1/1972, Dalloz, 1972, sec. Somm., p. 91; ídem, 23/11/1972, en JCP 1973-IV, p. 9; ídem, 5/7/1989, en JCP, 1989-IV, p. 339.

22 LE TOURNEAU, P, « Droit de la responsabilité et des contrats», cit, p. 467, Nro. 1376.
} 
En sentido concordante ha decidido el art. 1758 CCC, implícitamente, que las calidades de guardián y empleado son incompatibles; ello, dado que dicha norma indica que "Se considera guardián a quien ejerce, por sí o por terceros, el uso, la dirección y el control de la cosa...”.

El empleado ejerce en nombre de su patrón o principal el rol de guardián, pero no lo hace a nombre propio, por lo que no puede ser responsabilizado a ese título.

Avanzando en el análisis, cabe recordar que Patrice JOURDAIN afirma que "la guarda es una noción sutil, sin duda una de las más sutiles de nuestro derecho. Ella implica un cierto control, un cierto poder sobre las cosas, siendo conforme a la idea de que ella es la contrapartida de un poder. ¿Pero de qué poder se trata?23.

Es menester aclarar que el concepto de guardián que se adopte es, por regla, excluyente de otros. Dicho en palabras sencillas, como principio y salvo alguna excepción caracterizada, una misma cosa no ha de tener dos guardianes.

Una excepción a esta limitación es la guarda compuesta, que por caso, se da entre locador y locatario o en supuestos de derechos de uso, donde cada uno de los legitimados es guardián, en la medida de sus poderes y facultades, conformando un mosaico complejo de legitimación pasiva y de guardia.

Consideramos que en estos supuestos podrían ser demandados ambos, a mérito del criterio de que la víctima no tiene por qué investigar la mecánica del accidente y, en todo caso, serán los co-legitimados quienes deberán argumentar y probar acerca del incumplimiento de qué deber o facultad ha provocado el daño lo que, en todo caso, incidirá sobre las relaciones internas del grupo codeudor. ${ }^{24}$

Amén de ello, bien ha enseñado Yannick DAGORNE-LABBE que la jurisprudencia y la doctrina francesa han admitido el principio según el cual la calidad de guardián de una cosa no puede ser, en un momento dado, reconocida más a que a una sola persona. Este principio de carácter alternativo y no acumulativo de la guarda conoce sin embargo, en derecho positivo francés dos atenuaciones. ${ }^{25}$

Cabe la posibilidad de dividir la guarda de una misma cosa confiriendo a dos personas la calidad de guardianes, cuando cada uno lo sea de un aspecto de esa cosa. ${ }^{26}$

Se trata de la distinción -que veremos infra- entre la guarda de la estructura y el comportamiento, que tiene por efecto atribuir a la cosa dos guardianes, uno ejerciendo sus poderes sobre la estructura y otro sobre su comportamiento. ${ }^{27}$

\footnotetext{
23JOURDAIN, Patrice, « Les principes de la responsabilité civile », Edit. Dalloz, París, 2003, p. 82.

${ }^{24}$ En similar sentido, SC Mendoza, sala I, 09/05/1996, “Uriarte de Rodríguez, María c. Díaz Alegre Mauricio y otro”, LA LEY 1996-E, 236 y DJ 1996-2-1378.

${ }^{25}$ DAGORNE-LABBE, Yannick, “Absence de garde collective d'un voilier qui a fait naufrage lors d'une régate", Recueil Dalloz, t. 1991, sec. Jurisprudence, p. 367.

${ }^{26}$ Para ver esta temática con mayor profundidad, vid. LÓPEZ MESA, Marcelo, Acerca de algunas espinosas cuestiones sobre la guarda de la cosa, su transferencia y los efectos que ésta engendra, de próxima aparición en revista La Ley.

${ }^{27}$ DAGORNE-LABBE, Y., "Absence de garde collective d'un voilier ... ", cit. p. 367.
} 
Varias han sido las tesituras adoptadas sobre el concepto de guardián a adoptar; aclaramos que no vamos a entrar en divagaciones y sutilezas dignas de mejor ocasión, como a veces se ha detenido la magistratura y la jurisprudencia francesa, en pos de determinar el guardián de las cosas más variadas, en supuestos que a nosotros nos parecerían casi ridículos en algunos $\operatorname{casos}^{28}$ y excesivamente sutiles en otros. ${ }^{29}$

Otro tema es si la condición de guardián requiere el discernimiento. Nos parece, por nuestra parte, que un mínimo de discernimiento es condición esencial para el ejercicio de la guarda.

Digamos que, al menos el discernimiento para los hechos ilícitos es, a nuestro criterio, imprescindible para poder adjudicarle a alguien el rol de guardián, sin que ello sea una completa ficción o un cómodo expediente para hacer beneficencia con dinero ajeno. Por ende, entendemos que no puede ser guardián un menor que no haya cumplido la edad de diez años o un demente.

La Corte de Casación francesa, ha flexibilizado tanto la exigencia de discernimiento que ha terminado en algún caso considerando guardián de una cosa a un menor de tres años, lo que nos parece un dislate tanto a nosotros como al maestro LE TOURNEAU ${ }^{30}$, aún cuando no compartimos el criterio del maestro en cuanto a la virtual irrelevancia del discernimiento a los efectos de la guarda. Al menos no, en lo que al derecho argentino concierne.

Veamos la evolución de la tesitura de la Corte de Casación francesa. En el célebre arrêt Escoffier de 1947 afirmó el Tribunal que el discernimiento es necesario para la adquisición de la guarda: atento que tanto el uso y los poderes de dirección y de control de la obligación de guarda en el sentido del art. 1384, primera parte del Código Napoleón, como la imputación de una responsabilidad presumida, implican la facultad de discernimiento». $3^{1}$

Pero, luego "en la década de 1960, los vientos de la indemnización de las víctimas de dementes comenzaron a soplar". ${ }^{2}$

Y, entonces, en 1964 en el arrêt Trichard, la Corte gala cambió su postura y declaró responsable, bajo el fundamento del art. 1384, párrafo primero del Código Napoleón, al conductor de un automóvil que causó un accidente bajo una crisis de epilepsia, dando como fundamento

\footnotetext{
${ }^{28}$ Vid el debate sobre la responsabilidad del guardián de un puente en ruinas, a partir de un reclamo de pasajeros de una excursión que transgredieron la prohibición de penetrar en propiedad privada y a consecuencia de ellos sufrieron daños (conf. LACABARATS, Alain, "Responsabilité du gardien d'un pont en ruines qui s'effondre au passage de promeneurs ayant transgressé l'interdiction de pénétrer dans une propriété privée et responsabilité contractuelle des organisateurs de la promenade qui n'ont pas averti du danger", en Recueil Dalloz, t. 1997, sec. Sommaires commentés, p. 188). Nos parece que en ese caso no debiera imponerse responsabilidad alguna, sino que el daño es consecuencia absoluta de la intrusión de las propias víctimas donde no tenían derecho a estar, lo que configura o bien culpa de la víctima o bien asunción de riesgos por ellas, con efecto interruptor del nexo causal con relación al dueño y al guardián de la cosa, en ese caso, un puente. Vid las inteligentes aportaciones de DELEBECQUE, Philippe, “L'exonération partielle de la présomption de responsabilité pesant sur les gardiens d'une chose, la victime ayant commis une faute en ne veillant pas à sa propre sécurité”, en Recueil Dalloz, t. 1995, sec. Sommaires commentés, p. 232.

${ }^{29}$ Por ejemplo, puede verse el debate sobre la condición de guardián de una cosa abandonada en un camino -una mina que explotó- y la plétora de argumentos que se emplean en su derredor (vid. DELEBECQUE, P., "Responsabilité de la victime de l'explosion d'une mine ramassée dans une carrière non exploitée", Recueil Dalloz 1998, Sommaires commentés p. 202).

${ }^{30}$ LE TOURNEAU, «Droit de la responsabilité et des contrats», cit, pp. 1694/1695, Nro. 7834.

${ }^{31}$ Corte de Casación francesa, sala Civ., 28/4/1947, en Dalloz, t. 1947. p. 329, con nota del maestro Lalou.

32 PEAÑO, Marie-Annick, "L’incompatibilité...", cit. p. 51.
} 
que una obnubilación pasajera de las facultades intelectuales no es un evento susceptible de constituir una causa de daño exterior o extraño al guardián. ${ }^{33}$

Un nuevo paso en esta evolución hacia el abandono del discernimiento se dio en 1984 en el arrêt Gabillet. ${ }^{34}$

Ha expresado el maestro LE TOURNEAU: "Poder de hecho, la calidad de guardián puede incumbir bien a una persona física o a una persona moral. Ella no implica la capacidad jurídica ni la capacidad de discernimiento: por eso se ha sucesivamente reconocido como guardián a una persona que sufría de problemas mentales,...un menor e incluso un infante inconsciente (verdaderamente un exceso)...”. ${ }^{35}$

Nos parece que en esta cuestión como en otras se debe ser prudente y transaccional: exigir un completo discernimiento para ser guardián sería un exceso y dejaría un rosario de víctimas sin indemnización; pero pasarse al otro extremo y eliminar el requisito de un mínimo discernimiento -como el que se adquiere a los diez años, para los hechos ilícitos- es otro exceso, más peligroso incluso que el anterior.

Pese a todo, no conformes con los fundamentos dados por la Casación francesa, para abandonar la exigencia de discernimiento para la adquisición de la guarda, creemos que con los textos vigentes en nuestro país un mínimo de discernimiento continúa siendo requisito para que alguien se constituya en guardián, dado que no es la guarda una mera facticidad en el empleo de una cosa, sino que requiere de mínimas cualidades mentales, como para ser propiamente el guardián de una cosa.

Por último, cabe preguntarse cuna persona jurídica puede ser guardián de una cosa? Prestigiosa doctrina francesa se ha pronunciado favorablemente a este interrogante, expresando por caso el maestro LE TOURNEAU que "la asimilación de las personas morales a la de las personas físicas existe también en el terreno de la responsabilidad por el hecho de las cosas. Una persona moral puede ser responsabilizada como guardiana, en los términos del art. 1384 del Code, lo cual es una necesaria correspondencia con el principio de que los empleados no pueden ser guardianes". ${ }^{36}$

La agudeza del razonamiento es indudable, por lo que adherimos a él. De otro modo, realizar actividades con cosas riesgosas a través de sociedades comerciales, sería una forma indirecta de que nadie respondiera como guardián de la cosa, ni la sociedad ni sus empleados, lo que es conceptualmente inadmisible.

Por otra parte, no sería obstáculo para esta conclusión sobre la posible calidad de guardián de una sociedad mercantil, el texto del art. 1758 in medio del Proyecto de reformas: “... Se

\footnotetext{
${ }^{33}$ Cfr. Corte de Casación francesa, 2a sala Civ., 18/12/1964, Dalloz, 1965, p.191, con nota de Paul Esmein y en Juris Classeur Périod. 1965-II, nro. 14304, con nota de Noêl Dejean de la Bâtie.

${ }^{34}$ Corte de Casación, sala Civil, 9/5/1984, in re "Gabillet", en Dalloz, t. 1984, p. 525, con nota de François Chabas y en Juris Classeur Périod. t. 1984-II, nro. 20255, con nota de Noêl Dejean de la Bâtie.

${ }^{35}$ LE TOURNEAU, «Droit de la responsabilité et des contrats», cit, pp. 1694/1695, Nro. 7834.

${ }^{36}$ LE TOURNEAU, «Droit de la responsabilité et des contrats », p. 467, Nro. 1376.
} 
considera guardián a quien ejerce, por sí o por terceros, el uso, la dirección y el control de la cosa, o a quien obtiene un provecho de ella...”.

Si se analiza con objetividad la cuestión, la sociedad comercial puede ser guardián de la cosa, dado que ella ejerce por terceros (sus empleados o directivos) el uso, la dirección y el control de la cosa, amén de que ella obtiene provecho de la cosa.

A nuestro ver, el de guardián es un concepto que porta un importante grado de facticidad, de materialidad, aunque también es proficuo en nociones jurídicas. Es una noción en extremo flexible, elástica ${ }^{37}$, pero su posibilidad de extensión no es ilimitada.

La determinación concreta del concepto de guardián permanece compleja, pues desde el arrêt Franck se ha pasado de una definición simple de la guardia jurídica a una determinación más compleja y ambigua de la guardia material. Esto obliga a una armonización de ambas dimensiones de la guarda, en un concepto flexible y variable, según el caso concreto que se tenga delante, lo que hace que las muletillas y los preconceptos sean en esta temática muy peligrosos, siendo la determinación del guardián en cada caso concreto artesanal, y debiendo ser el juez el artesano que la talle sobre materiales nobles y con la paciencia de un orfebre, para responder adecuadamente y lo mejor posible a la realidad de los hechos.

No puede ser guardián, en ningún caso, quien no ostenta, jurídicamente o de hecho, al momento del hecho dañoso, una "esfera de autoridad" sobre la cosa dañosa. ${ }^{38}$

\section{III) EL GUARDIÁN DE LA ESTRUCTURA Y DEL COMPORTAMIENTO}

Además de las teorías tradicionales - de la guarda material, de la guarda jurídica, de la guarda-provecho, que damos por suficientemente conocidas- algunos autores, y en ocasiones la jurisprudencia, distinguen dos clases de guardia:

a) la guarda de la estructura; $y$

b) la guarda del comportamiento.

La guarda de la estructura se refiere a la responsabilidad por la materia que compondría la cosa, el poder de control sobre los vicios de la cosa. En cambio, la guarda del comportamiento atañe al funcionamiento de la cosa, a la responsabilidad derivada de su utilización. El guardián del comportamiento no es necesariamente guardián de la estructura. ${ }^{39}$

La tesitura del caso "Franck" pareció ser satisfactoria durante un tiempo, pero luego se apreció que ese criterio podía producir consecuencias injustas en algunos supuestos, como en

\footnotetext{
${ }^{37}$ BUFFELAN-LANORE, Yvaine - LARRIBAU-TERNEYRE, Virginie, “Droit civil. Les obligations”, 12a edic., Edit. Sirey, París, 2010, p. 678, Nro. 1967.

${ }^{38}$ BRUN, Philippe, "Responsabilité civile extracontractuelle", 3ạ edic. Edit. Litec - Lexis Nexis, París, 2014, p. 244, Nro. 372.

${ }^{39} \mathrm{Cfr}$. https://actu.dalloz-etudiant.fr/a-la-une/article/responsabilite-du-fait-des-choses-abandon-de-la-theorie-de-lacceptationdes-risques/h/4592f8dcc5b448ea06637e7890aad733.html
} 
los accidentes sobrevenidos por el vicio interno de la cosa, en los que el guardián indudablemente no podía ser tenido por responsable. Cabe preguntarse ces razonable considerar culpable a un automovilista por la ruptura imprevista de la barra de dirección de su auto, si ella se produce a consecuencia de un defecto en el armado del rodado? ${ }^{40}$

De ahí que, en miras de hacer recaer la responsabilidad sobre los verdaderos responsables, la jurisprudencia a partir del caso del "oxígeno líquido"41 y algunos autores admitieron la posibilidad de dividir la guarda de una cosa entre distintas personas: para los accidentes debidos a un vicio de construcción o de compostura, o del material, habría una guarda de la estructura de la cosa considerada en sí misma, que asumiría el propietario o el fabricante. En tanto que se trataría de una guarda del comportamiento o de la utilización, para los siniestros vinculados con el movimiento o la manipulación de una cosa, que recaería en el encargado de la dirección y control de su funcionamiento y comportamiento..$^{2}$

Es decir, que la guarda podría disociarse y atribuirse separadamente a distintas personas, teniendo en cuenta la causa del daño y según el poder que cada una de ellas pudo tener sobre la cosa en cuestión. Por caso, si un vehículo alquilado provoca un daño por defectos o vicios del mismo, el propietario y locador del vehículo debe responder como "guardián de su estructura"; en tanto que si la causa del perjuicio ha sido el mal manejo del coche o el hecho de haberlo dejado incorrectamente estacionado en un lugar peligroso para el tránsito, habrá de ser el locatario el obligado a resarcir tal daño a la víctima.

La Suprema Corte mendocina ha declarado en un fallo que la distinción entre guardián de la estructura y del comportamiento es irrelevante en las relaciones víctima, terceros y guardián, pero puede adquirir importancia en las acciones entre los co-guardianes. El guardián de la estructura es aquel que tiene la dirección y gobierno de la cosa en su aspecto estático o composición interna; él responde por los daños producidos por los defectos que posea y se trate del propietario, fabricante, encargado del mantenimiento, etc., de la cosa. El guardián del comportamiento, es el tenedor que manipula la cosa, la conduce o dirige y al hacerlo puede incurrir en un error o uso defectuoso. ${ }^{43}$

Un interesantísimo caso, encuadrable en este anaquel, fue el fallado por la justicia francesa (Corte de Casación, ${ }^{a}$ sala Civil, 4/3/1998), en un caso en que a consecuencia de una separación de cuerpos, en un matrimonio que estaba pasando por momentos difíciles, el esposo hizo volar con explosivos la casa de su esposa. Esta explosión significó la proyección de los daños a un inmueble vecino, por lo que los propietarios de éste reclamaron contra los dos

\footnotetext{
${ }^{40}$ C STARCK, Boris - ROLAND, Henri - BOYER, Laurent, “Obligations”, 4a ed. París, Litec. 1991, T. 1, p. 259 , № 575.

${ }^{41}$ En este caso se trató de la explosión de una botella metálica llena de oxígeno líquido comprimido, mientras era transportada en ruta, provocando heridas graves a un empleado de la destinataria de la mercadería y a otro de la empresa transportista (cfr. STARCK-ROLAND-BOYER, Obligations, cit., T. 1, pp. 261 y s., №s. 580 y ss.).

${ }^{42}$ STARCK-ROLAND-BOYER, Obligations, cit., T. 1, pp. 259 y s., № 575; KEMELMAJER DE CARLUCCI, en Código Civil..., cit., de BELLUSCIO-ZANNONI, T. 5, pp. 471 y s., $§ 19$.

${ }^{43}$ SC Mendoza, sala I, 09/05/1996, “Uriarte de Rodríguez, María c. Díaz Alegre Mauricio y otro”, LA LEY 1996-E, 236 y DJ 1996-2-1378.
} 
esposos separados la responsabilidad por los daños con fundamento en el art. 1384 (resp. por el hecho de las cosas), que admite la calidad de guardián del inmueble del esposo en tanto propietario de éste. La Corte de Casación exoneró de responsabilidad a la esposa, en decisión criticada en el comentario al fallo, bajo el argumento de que el esposo que dispone de medios de derecho para excluir o limitar su propia responsabilidad y no los emplea no puede ser exonerado de responsabilidad. ${ }^{44}$

Si bien no participamos de esta teoría de la guarda disociada hasta sus últimas consecuencias y entendemos que ella no puede ser conjeturada en su aplicación a ciertos supuestos, debiendo existir un régimen normativo que brinde margen interpretativo suficiente para su empleo, no se aprecia desatinada la solución de la Segunda Sala Civil. Todo lo contrario, porque mantener la guarda al punto de responder por daños causados por explosivos puestos por un enemigo -evidentemente a ese punto habían llegado los esposos- es más que mantener la guarda, plasmar una ficción especiosa.

Reiteramos, no nos parece descabellado el criterio de la Casación francesa y sí, en cambio, nos merece el calificativo de ocurrencia el fallo de Cámara que la Casación revocara y que había mantenido la responsabilidad de la esposa por los daños causados por explosivos dirigidos contra ella.

\section{IV) OBSERVACIONES}

Dejando de lado la pretensión de formular de manera general y abstracta el concepto de "guardián”, circunscribiéndonos a nuestro derecho privado positivo, serán las circunstancias del caso las que determinen quién será tenido por guardián, al encajar en alguna de las formas legamente acogidas de guarda.

Son directivas a tener en cuenta para tallar la figura del guardián: ante todo la noción de provecho, colocada en último lugar por el texto legal, pues servirse es valerse de una cosa para el uso de ella o sea aprovechar de la misma; en segundo término, y principalmente, la noción de uso de la cosa, que habrá de adquirir de hecho especial relevancia en la materia, dada la facilidad de la prueba de sus presupuestos.

Y, subsidiariamente, la pauta de la dirección y control de la cosa, aplicable cuando los anteriores criterios resulten insuficientes, porque, verbigracia, más de una persona obtiene beneficios por distintos títulos de la misma cosa, como ocurre en el recordado caso del locador y locatario, o por cualquier otro motivo.

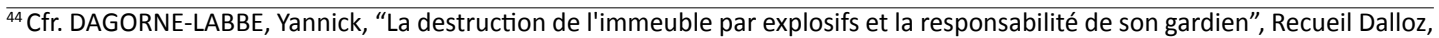
t. 1999, sec. Jurisprudence, p. 217. 
Creemos que este es el entendimiento a dar al art. 1758 CCC, en la parte que exime de responsabilidad al dueño o guardián "si la cosa hubiese sido usada contra su voluntad expresa o presunta”; ya que entonces ellos ya no se sirven más de la cosa, ni pueden hacerlo, y sí por el contrario aprovecha de la misma quien la usa en su propio beneficio contra la voluntad de aquellos.

Tal la vez los anteriores desarrollos sirvan en algún caso concreto para orientar una decisión que, a la luz de la parquedad y promiscuidad de conceptos de guarda del nuevo texto del art. 1758 CCC, puede aparecer confusa. Esperamos que así sea.

\section{CURRICULUM VITAE}

\section{Marcelo J. López Mesa}

Doctor en Derecho y Ciencias Sociales (UNLP) - Académico correspondiente de las Academias Nacionales de Derecho y Ciencias Sociales de Buenos Aires y de Córdoba - Académico no numerario de la Real Academia de Jurisprudencia y Legislación (Galicia, España) - Profesor Titular de Derecho Civil en la Universidad de Belgrano y en la Universidad Maimónides - Profesor visitante de las Universidades Washington University (EEUU), Rey Juan Carlos y de La Coruña (España), de París XIII (Sorbonne-París Cité) y Savoie (Francia), de Coimbra (Portugal), de Perugia (Italia), Católica del Perú, Pontificia Javeriana (Colombia), de la República (Uruguay), etc. - Autor de treinta libros en temas de Derecho Civil y Procesal Civil.

marcelo.lopezmesa@gmail.com 